\title{
PRODUTIVIDADE E RENTABILIDADE DO MANGARITO SOB DIFERENTES DENSIDADES DE PLANTIO E FONTES DE RESÍDUO ORGÂNICO
}

\author{
Productivity and profitability of tannia under different densities and sources of organic residue
}

\author{
Lovaine Fiel de Quevedo Castro ${ }^{1}$, Néstor Antonio Heredia Zárate ${ }^{2}$, Maria do Carmo Vieira ${ }^{2}$, Elissandra Pacito \\ Torales $^{2}$, Lais de Lima Luqui ${ }^{2}$
}

\begin{abstract}
${ }^{1}$ Centro Universitário da Grande Dourados (Unigran), Dourados-MS, Brasil, lquevedo@unigran.br; ${ }^{2}$ Universidade Federal da Grande Dourados (UFGD), Dourados-MS, Brasil, nestorzarate@ufgd.edu.br; mariavieira@ufgd.edu.br, ninapacito@hotmail.com, lais_luqui@hotmail.com
\end{abstract}

Artigo enviado em 12/02/2017, aceito em 19/06/2017 e publicado em 29/09/2017.

Resumo - O objetivo deste trabalho foi avaliar a influência de diferentes espaçamentos entre plantas $(12,5 ; 15,0 ; 17,5$ e 20,0 cm) e tipos de cama de frango adicionadas ao solo (com bases maravalha e casca de arroz e sem cama de frango), na produtividade e rentabilidade do mangarito. Os tratamentos foram arranjados no esquema fatorial $4 \times 3$, no delineamento experimental blocos casualizados, com quatro repetições. As maiores produtividades foram obtidas sob o menor espaçamento $(12,5 \mathrm{~cm})$, apresentando valores máximos de $1,25 \mathrm{t} \mathrm{ha}^{-1}$, para rizoma mãe e 4,20 $\mathrm{t} \mathrm{ha}{ }^{-1}$, para rizoma filho comercializável, com aumentos de 0,59 e 2,78 $\mathrm{t} \mathrm{ha}^{-1}$, respectivamente, em relação ao espaçamento de $20 \mathrm{~cm}$ entre plantas. Os custos estimados para produzir 1,0 ha de mangarito variaram em $\mathrm{R} \$ 1.619,06$, entre o maior custo ( $\mathrm{R} \$$ 9.917,36), para o cultivo sob espaçamento de $12,5 \mathrm{~cm}$ e o menor custo ( $\$$ \$ 8.298,30), sob espaçamento de $20 \mathrm{~cm}$, sem a adição de cama de frango. Para se obter maior produtividade de rizomas comercializáveis e maiores renda bruta e líquida, o cultivo de mangarito deve ser feito no espaçamento de $12,5 \mathrm{~cm}$ entre plantas e com cama de frango com base de casca de arroz.

Palavras-chave: Xanthosoma mafaffa, espaçamentos, adubação orgânica, renda.

Abstract - The aim of this study was to evaluate the influence of different spacing arrangement between plants $(12.5,15.0,17.5$ and $20.0 \mathrm{~cm})$ and types of broiler manure (with base residue shavings and rice hulls added in soil cover and without the addition of broiler manure), in the productivity and profitability of tannia. The treatments were arranged in a $4 \times 3$ factorial scheme, in a randomized complete block design, with four replications. The highest yields were obtained in the smallest spacing $(12.5 \mathrm{~cm})$, presenting maximum values of $1.25 \mathrm{t} \mathrm{ha}^{-1}$, for the mother cormel and $4.20 \mathrm{t} \mathrm{ha}^{-1}$, for commercial cormels, with increases of 0.59 and $2.78 \mathrm{t} \mathrm{ha}^{-1}$, respectively, in relation to the spacing of $20 \mathrm{~cm}$ between plants, which was the one that obtained the lowest productive means. The costs estimated to produce 1.0 ha of tannia as a function of the treatments under study varied by $R \$ 1,619.06$ between the highest cost $(\mathrm{R} \$ 9,917.36)$, determined for cultivation in spacing of $12.5 \mathrm{~cm}$ and the lowest cost $(\mathrm{R} \$ 8,298.30)$, for cultivation at $20 \mathrm{~cm}$ spacing without the addition of broiler manure to the soil. In order to obtain higher yields and higher gross and net income of commercial cormels of tannia, the cultivation should be done at a spacing of $12.5 \mathrm{~cm}$ between plants and with addition of broiler manure with of rice husk base residue.

Keywords - Xanthosoma mafaffa, spacing, organic fertilizer, income.

\section{INTRODUÇÃO}

O cultivo do mangarito (Xanthosoma mafaffa Schott) no Brasil tem sido feito principalmente na agricultura de subsistência, em hortas domésticas e por pequenos agricultores, assumindo importância étnica, cultural e econômica (HEREDIA ZÁRATE; VIEIRA; PONTIM, 2005). Considerado por gastrônomos uma iguaria (FRAGATA, 2012), os rizomas são consumidos cozidos, ensopados com carnes e ao molho e seu valor nutricional é comparável ao da batata (Solanum tuberosum) (COSTA et al. 2008; KINUPP; LORENZI, 2014). 
No cultivo de hortaliças, vem se destacando o uso de cobertura morta ou mulching, que consiste em adicionar ao solo material orgânico como cobertura da superfície, beneficiando os atributos físicos, químicos e biológicos do solo (MANGIORI e FILHO, 2015). Na parte física, auxilia no aumento da porosidade e protege a superfície do solo do impacto de pingos de chuva, reduzindo a erosão e aumentando o armazenamento de água no perfil do solo (CHEN et al., 2014); na parte química, auxilia na liberação gradual e na maior diversidade dos nutrientes, devido às variadas composições. Em relação aos efeitos na parte biológica, em função da maior disponibilidade de nutrientes, ocorre o aumento da atividade biológica (HOSHINO et al., 2016) tornando-se um excelente adubo para ser usado na agricultura familiar.

Dentre as informações sobre os tratos culturais relevantes para produção do mangarito, está a população de plantas, visando manter ou aumentar a produtividade da cultura (TERRA et al., 2010). Pode ser ajustada por meio do espaçamento entre as linhas e pelo aumento da densidade de plantas nas linhas de plantio (ROCHA; FILHO; BARBOSA, 2011). A população de plantas tem efeito marcante sobre a produção final, já que a competição por água, luz e nutrientes pode contribuir para a redução da capacidade produtiva das plantas, incidindo em maior ou menor grau na produtividade das diferentes espécies (HEREDIA ZÁRATE et al., 2006).

Segundo Costa et al. (2008), o mangarito só é comercializado sazonalmente, em locais próximos às áreas de produção. Todavia, progressos que levem ao aumento da produção poderão torná-lo popular para o mercado hortigranjeiro. Melo et al. (2009) citam que em qualquer atividade econômica é essencial o estudo da rentabilidade e o acompanhamento dos custos de produção para a melhor competitividade no mercado. Assim, uma atividade agrícola é interessante quando propiciar retorno financeiro superior ao custo de produção.

Objetivou-se com o presente estudo avaliar a produtividade e rentabilidade do mangarito sob o cultivo com diferentes espaçamentos entre plantas $e$ tipos de cama de frango com diferentes bases.

\section{MATERIAL E MÉTODOS \\ Descrição da área de estudo}

O experimento foi realizado entre setembro de 2013 e junho de 2014, no Horto de Plantas Medicinais, da Faculdade de Ciências Agrária - FCA, da Universidade Federal da Grande Dourados, Dourados, MS. A área experimental situa-se nas coordenadas geográficas $22^{\circ} 11^{\prime} 44^{\prime \prime} \mathrm{S}$ e $54^{\circ} 56^{\prime} 08^{\prime \prime} \mathrm{W}$ e altitude de $430 \mathrm{~m}$. O clima da região, seguindo classificação Köppen-Geiger, é do tipo Aw (PEEL; FINLAYSON; MCMAHON, 2007) com médias anuais para precipitação e temperatura de $1425 \mathrm{~mm}$ e $23,6^{\circ} \mathrm{C}$, respectivamente. $\mathrm{O}$ solo foi classificado como Latossolo Vermelho Distroférrico, textura muito argilosa (EMBRAPA, 2013), com teores de M.O. $=3,2 \mathrm{~g} \mathrm{dm}^{-3} ; \mathrm{P}=6,0 \mathrm{mg} \mathrm{dm}^{-3} ; \mathrm{K}=3,0 ; \mathrm{Ca}=39,7$ e $\mathrm{Mg}=28,2 \mathrm{mmol}_{\mathrm{c}} \mathrm{dm}^{-3}$ e $\mathrm{pH}$ em $\mathrm{H}_{2} \mathrm{O}=6,1$. A análise química dos tipos de cama de frango semidecompostas com diferentes bases, utilizadas no experimento são apresentados na Tabela 1.

Tabela 1 - Atributos químicos de amostras de cama de frango com bases maravalha e casca de arroz, antes do plantio do mangarito.

\begin{tabular}{lcc}
\hline Atributos químicos & Maravalha & $\begin{array}{c}\text { Casca de } \\
\text { arroz }\end{array}$ \\
\hline $\mathrm{N}(\%)$ & 1,58 & 1,61 \\
$\mathrm{P}\left(\mathrm{g} \mathrm{kg}^{-1}\right)$ & 15,30 & 10,80 \\
$\mathrm{~K}\left(\mathrm{~g} \mathrm{~kg}^{-1}\right)$ & 16,80 & 24,63 \\
$\mathrm{Ca}\left(\mathrm{g} \mathrm{kg}^{-1}\right)$ & 19,29 & 12,04 \\
$\mathrm{Mg}\left(\mathrm{g} \mathrm{kg}^{-1}\right)$ & 8,50 & 5,90 \\
$\mathrm{Cu}\left(\mathrm{mg} \mathrm{kg}^{-1}\right)$ & 33,70 & 53,10 \\
$\mathrm{Fe}\left(\mathrm{g} \mathrm{kg}^{-1}\right)$ & 6,06 & 1,04 \\
$\mathrm{Mn}\left(\mathrm{mg} \mathrm{kg}^{-1}\right)$ & 871,00 & 422,00 \\
$\mathrm{Zn}\left(\mathrm{mg} \mathrm{kg}^{-1}\right)$ & 414,00 & 299,00 \\
\hline
\end{tabular}

Foram cultivadas plantas de mangarito 'Comum' sob quatro espaçamentos: 12,5; 15,0; 17,5 e $20,0 \mathrm{~cm}$ e sob diferentes tipos de cama de frango em cobertura do solo, com diferentes bases: $10 \mathrm{t} \mathrm{ha}^{-1} \mathrm{de}$ maravalha; $10 \mathrm{t} \mathrm{ha}^{-1}$ casca de arroz e sem cama de frango. Os tratamentos foram arranjados no esquema fatorial $4 \times 3$, no delineamento experimental blocos casualizados, com quatro repetições. Cada parcela possuía 1,5 $\mathrm{m}$ de largura por 1,5 $\mathrm{m}$ de comprimento, sendo a largura efetiva do canteiro de $1,0 \mathrm{~m}$, com três fileiras de plantas espaçadas de $0,33 \mathrm{~m}$. As populações correspondentes ao plantio, de $12,5,15,0,17,5$ e 20,0 $\mathrm{cm}$ entre plantas dentro da fileira foram de 158.400 , 132.066, 113.256 e 99.000 plantas $\mathrm{ha}^{-1}$, respectivamente.

Para a implantação do experimento, o solo foi preparado duas semanas antes do plantio, com uma aração e uma gradagem e levantamento dos canteiros com rotoencanteirador.

O plantio foi realizado manualmente e de forma direta na área do experimento, utilizando propágulos formados por rizomas filhos inteiros, obtidos na área do Horto de Plantas Medicinais da UFGD, com massa média de 1,90 g. Para o plantio, foi utilizada a metodologia de Heredia Zárate et al. 
(2013), sendo abertos sulcos de $0,05 \mathrm{~m}$ de largura $\times 0,05 \mathrm{~m}$ de profundidade e posteriormente, colocados os propágulos no fundo do sulco, com a gema apical para cima e cobertos com o solo extraído na abertura dos sulcos. Logo em seguida, foi realizada a distribuição em cobertura das camas de frango nas respectivas parcelas.

Durante o ciclo da cultura, foram feitas irrigações por aspersão a cada dois dias e, nos últimos dois meses, duas vezes por semana. A vegetação espontânea foi controlada por meio de capinas entre os canteiros e, manualmente, dentro dos canteiros.

A colheita foi realizada quando as plantas de mangarito apresentaram em torno de $90 \%$ das folhas amareladas e secas, sintomas típicos de senescência, o que aconteceu aos 243 dias após o plantio. Foram avaliadas a produtividade de massa fresca dos rizomas mãe e dos rizomas filhos comercializáveis $(>2,1 \mathrm{~g})$ e não comercializáveis $(<\quad 2,0 \quad \mathrm{~g} \quad \mathrm{e}$ refugos $)$, comprimento $(\mathrm{mm})$ e diâmetro $(\mathrm{mm})$ dos rizomas filhos comercializáveis e não comercializáveis.

Os dados de produtividade foram submetidos à análise de variância e, quando significativos pelo teste $\mathrm{F}$, submetidos à análise de regressão em função dos espaçamentos entre plantas, e pelo teste de Tukey, em função dos tipos de resíduo a base de cama de frango, todos a 5\% de probabilidade. Utilizou-se o software SISVAR (FERREIRA, 2011).

Para a análise econômica, foram realizadas estimativas dos custos de produção e das rendas bruta e líquida em função das produtividades dos rizomas filhos comercializáveis das plantas de mangarito. Para o cálculo da renda bruta, foi utilizado o preço de $\mathrm{R} \$$ $3,00 \mathrm{~kg}^{-1}$ de rizomas filhos comercializáveis, pago aos produtores do Paraná, em agosto de 2014. Os custos de produção foram calculados usando tabela adaptada de Gassi et al. (2014). A renda líquida foi determinada pela renda bruta menos os custos de produção por hectare cultivado.

\section{RESULTADOS E DISCUSSÃO Produtividade}

As massas frescas de rizomas mães (RM) e rizomas filhos comercializáveis (RFC) de plantas de mangarito não foram influenciadas significativamente pelos tipos de cama de frango (Tabela 2), apresentando médias de 0,81 e 3,49 t ha-1, respectivamente. Por outro lado, os espaçamentos entre plantas influenciaram as produtividades (Figura 1), sendo as maiores obtidas sob o menor espaçamento (12,5 cm entre plantas), resultando em valores máximos de 1,25 $\mathrm{t} \mathrm{ha}^{-1}$, para rizomas mães e $4,20 \mathrm{t} \mathrm{ha}^{-1}$, para rizomas filhos comercializáveis, com aumentos de 0,59 e 2,78 t ha $^{-1}$, respectivamente, em relação ao espaçamento de $20 \mathrm{~cm}$ entre plantas, que resultou nas menores médias produtivas. Já, a massa fresca de rizomas filhos não comercializáveis (RFNC) não foi influenciada pelos fatores em estudo, apresentando média de $0,44 \mathrm{t} \mathrm{ha}^{-1}$ (Figura 1).

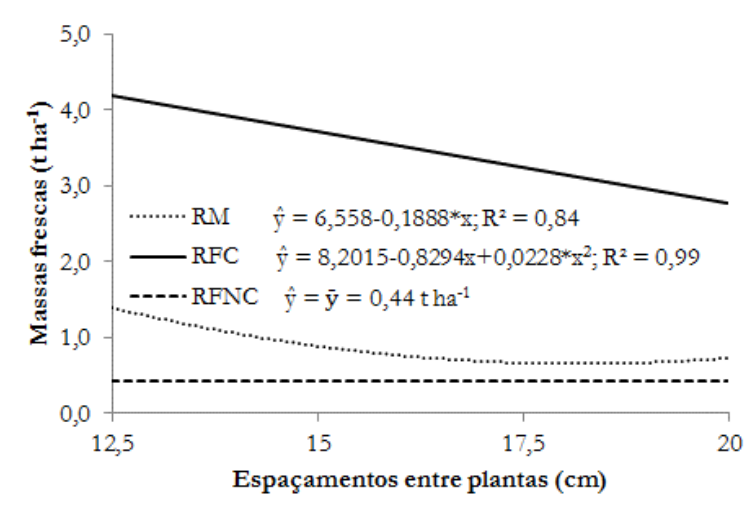

Figura 1 - Massa fresca de rizoma mãe (RM), rizoma filho comercializável (RFC) e rizoma filho não comercializável (RFNC) de plantas de mangarito cultivado sob diferentes espaçamentos.

As maiores produtividades obtidas sob o menor espaçamento entre plantas $(12,5 \mathrm{~cm})$, ou seja, uma maior população de plantas, estão de acordo com dados obtidos por Peixoto et al. (2008), que verificaram que a densidade de plantas na linha é um fator modificador da arquitetura da planta, permitindo que estas se adaptem a diferentes condições de cultivo. Os resultados estão de acordo com Gassi (2010) que, ao avaliar a produtividade do mangarito, em função de espaçamentos entre plantas $(10$ e $15 \mathrm{~cm})$, obteve maiores valores de $\mathrm{RM}(1,95 \mathrm{t}$ $\left.\mathrm{ha}^{-1}\right)$ e RF totais $\left(6,33 \mathrm{t} \mathrm{ha}^{-1}\right)$, sob o menor espaçamento estudado, de $10 \mathrm{~cm}$. Já, Gassi et al. (2014) obtiveram maior massa fresca de RF grandes quando utilizaram maior espaçamento entre plantas $(15 \mathrm{~cm})$, superando em $0,84 \mathrm{t} \mathrm{ha}^{-1}$ à obtida no espaçamento de $10 \mathrm{~cm}$ entre plantas.

Os aumentos nas produtividades de RM e RFC podem ser atribuídos, além da maior quantidade de plantas por área, à distribuição mais equidistante de plantas na área. Isso aumenta a eficiência de utilização da luz solar, água e nutrientes, ocorre o fechamento mais rápido dos espaços disponíveis e melhora o controle de plantas daninhas (EMBRAPA, 2010), contribuindo para o maior desenvolvimento das plantas. 
O comprimento de RFC de mangarito foi influenciado pela interação espaçamentos entre plantas e tipos de cama de frango com diferentes bases, apresentando curvas de crescimento quadráticas (Figura 2). $\mathrm{O}$ maior comprimento máximo $(31,36 \mathrm{~mm})$ foi dos rizomas de plantas cultivadas no espaçamento de $12,5 \mathrm{~cm}$, com a adição de cama de frango base maravalha. Os diâmetros dos rizomas não foram influenciados pelos fatores em estudo e por isso é apresentada a média dos valores obtidos e que correspondeu a 9,16 (não comercializável) e 17,87 mm (comercializável).

Tabela 2 - Massas frescas de rizoma mãe (RM), rizoma filho comercializável (RFC) e rizoma filho não comercializável (RFNC) de plantas de mangarito cultivado sob diferentes tipos de cama de frango com diferentes bases.

\begin{tabular}{lccc}
\hline & \multicolumn{3}{c}{ Massas frescas $\left(\mathrm{t} \mathrm{ha}^{-1}\right)$} \\
\cline { 2 - 4 } & $\mathrm{RM}$ & $\mathrm{RFC}$ & $\mathrm{RFNC}$ \\
\hline \multicolumn{1}{l}{ Tipos de resíduo } & & \\
\hline Maravalha & $0,84 \mathrm{a}^{*}$ & $2,99 \mathrm{a}$ & $0,40 \mathrm{a}$ \\
Casca arroz & $0,89 \mathrm{a}$ & $4,13 \mathrm{a}$ & $0,44 \mathrm{a}$ \\
Testemunha & $0,69 \mathrm{a}$ & $3,34 \mathrm{a}$ & $0,49 \mathrm{a}$ \\
\hline C.V. $(\%)$ & 31,83 & 45,25 & 44,0 \\
\hline
\end{tabular}

*Médias seguidas pelas mesmas letras, nas colunas, não diferem entre si pelo teste de Tukey, a $5 \%$ de probabilidade.

O maior comprimento dos RFC de plantas de mangarito cultivadas com cama de frango base maravalha, quando comparado com a casca de arroz, pode estar relacionado com maiores teores de $\mathrm{P}, \mathrm{Ca}$, $\mathrm{Mg}$ e Fe da cama de frango (Tabela 1). Os resultados são coerentes com os dos estudos realizados por Torales et al. (2014) e Heid et al. (2015), que observaram elevação do $\mathrm{P}, \mathrm{K}$ e $\mathrm{Mg}$ do solo após aplicação de cama de frango, ao avaliaram seu efeito na produção e comprimento de raízes comercializáveis de mandioquinha-salsa, que também é uma tuberosa. Já, o menor valor obtido sob o maior espaçamento entre plantas está de acordo com Fontes et al. (2012) que, ao avaliarem a produtividade de batata em resposta às variações no espaçamento entre linhas, observaram que a quantidade de tubérculo comercial por área decresceu exponencialmente com o aumento do espaçamento entre plantas. Esses autores atribuíram esse aumento de tubérculos pelo aumento da população de plantas, e como consequência, há aumento da área foliar na absorção de radiação, sem competição, que é importante variável determinante do crescimento das plantas e amplamente utilizada nos modelos matemáticos de produtividade (PEREIRA et al., 2008).
Taiz e Zeiger (2013) e Rocha (2008) relatam que sob populações de plantas maiores, a produção das culturas é reduzida pelo sombreamento das folhas baixeiras, devido à menor quantidade de radiação solar que recebem, fato que não foi observado com o mangarito, no qual os melhores resultados foram obtidos com a maior população de plantas. Esse resultado pode estar relacionado à arquitetura das folhas das plantas do mangarito, que são semi eretas, sombreando pouco umas às outras.

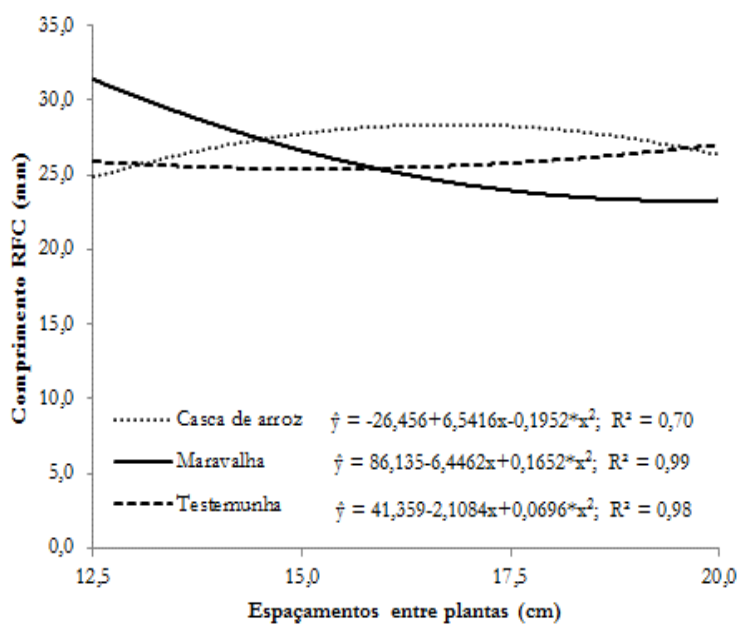

Figura 2 - Comprimento de rizoma filho comercializável (RFC) de plantas de mangarito cultivado sob diferentes espaçamentos entre plantas e tipos de cama de frango com diferentes bases.

\section{Custos de produção e rentabilidade}

Para produzir 1,0 ha de mangarito, os custos variaram em $\mathrm{R} \$ 1.619,06$, entre o maior custo ( $\mathrm{R} \$$ $9.917,36)$, para o cultivo sob espaçamento de $12,5 \mathrm{~cm}$ e o menor custo ( $\mathrm{R} \$ 8.298,30)$, sob espaçamento de $20 \mathrm{~cm}$, sem a adição de cama de frango (Tabelas $3 \mathrm{e}$ 4 , respectivamente).

O maior custo variável, determinado para o cultivo em espaçamento de $12,5 \mathrm{~cm}$, independente do tipo de cama de frango adicionada, representou $68,47 \%$ ( $\mathrm{R} \$ 6.790,09)$ do custo total de produção ( $\mathrm{R} \$$ 9.917,36) (Tabela 4). O menor custo variável, no cultivo com $20 \mathrm{~cm}$ entre plantas, sem a cama de frango, representou $65,53 \%$ ( $\mathrm{R} \$ 5.438,10)$ do custo total de produção ( $\mathrm{R} \$ 8.298,30$ ) (Tabela 3). Essas diferenças estão relacionadas com as quantidades de insumos, mão de obra e maquinários utilizados nos diferentes tratamentos utilizados durante o período 
de preparo das mudas e condução do experimento em campo.

O maior custo com a mão de obra $(\mathrm{R} \$$ $6.600,00)$ representou 40,38\% do custo total de produção ( $\mathrm{R} \$ 9.917,36)$ (Tabela 4) e, o menor ( $\mathrm{R} \$$ $3.780,00)$, representou $45,60 \%$ do custo total de produção (R\$ 8.298,30) (Tabela 3). Essa variação se deve principalmente à distribuição da cama de frango e à produção no campo, que variaram conforme $o$ espaçamento adotado.
Os custos fixos $(\mathrm{R} \$ 1.714,50)$ representaram $20,66 \%$ do custo total de produção no cultivo com espaçamento de $20 \mathrm{~cm}$ entre plantas, sem a adição de cama de frango ao solo (Tabela 3) e 17,28\% do custo total de produção em espaçamento de $12,5 \mathrm{~cm}$, independentemente do tipo de cama de frango adicionada ao solo (Tabela 4).

Tabela 3 - Custos de produção de um hectare de mangarito cultivado sem o uso da cama de frango e sob diferentes espaçamentos entre plantas.

\begin{tabular}{|c|c|c|c|c|c|c|c|c|}
\hline \multirow{2}{*}{$\begin{array}{l}\text { Espaçamento }(\mathrm{cm}) \\
\text { 1. Custos Variáveis }\end{array}$} & \multicolumn{2}{|c|}{12,5} & \multicolumn{2}{|c|}{15} & \multicolumn{2}{|c|}{17,5} & \multicolumn{2}{|c|}{20} \\
\hline & Quant. & Custo $(\mathrm{R} \$)$ & Quant. & Custo $(\mathrm{R} \$)$ & Quant. & Custo $(\mathrm{R} \$)$ & Quant. & Custo $(\mathrm{R} \$)$ \\
\hline \multicolumn{9}{|l|}{ Insumos } \\
\hline Mudas $^{1}$ & 302,54 & 605,09 & 252,25 & 504,50 & 216,32 & 432,64 & 189,09 & 378,18 \\
\hline Cama de frango ${ }^{2}$ & - & - & - & - & - & - & - & - \\
\hline Subtotal $(\mathrm{R} \$)$ & - & 605,09 & - & $\mathbf{5 0 4 , 5 0}$ & - & 432,64 & - & 378,18 \\
\hline Mão-de-obra & $\mathrm{H} / \mathrm{D}$ & $(\mathrm{R} \$)$ & $\mathrm{H} / \mathrm{D}$ & $(\mathrm{R} \$)$ & $\mathrm{H} / \mathrm{D}$ & $(\mathrm{R} \$)$ & $\mathrm{H} / \mathrm{D}$ & $(\mathrm{R} \$)$ \\
\hline Preparo das mudas & 8,00 & 360,00 & 8,00 & 360,00 & 8,00 & 360,00 & 8,00 & 360,00 \\
\hline Plantio & 16,00 & 720,00 & 16,00 & 720,00 & 16,00 & 720,00 & 16,00 & 720,00 \\
\hline Distribuição da CF & - & - & - & - & - & - & - & - \\
\hline Irrigação & 10,00 & 450,00 & 10,00 & 450,00 & 10,00 & 450,00 & 10,00 & 450,00 \\
\hline Capinas & 20,00 & 900,00 & 20,00 & 900,00 & 20,00 & 900,00 & 20,00 & 900,00 \\
\hline Colheita & 30,00 & 1350,00 & 30,00 & 1350,00 & 30,00 & 1350,00 & 30,00 & 1350,00 \\
\hline Subtotal $(\mathrm{R} \$)$ & - & $3.780,00$ & - & $3.780,00$ & - & $3.780,00$ & - & $3.780,00$ \\
\hline \multicolumn{9}{|l|}{ Maquinários } \\
\hline Bomba de irrigação & $80,00 \mathrm{~h}$ & 800,00 & $80,00 \mathrm{~h}$ & 800,00 & $80,00 \mathrm{~h}$ & 800,00 & $80,00 \mathrm{~h}$ & 800,00 \\
\hline Trator preparo & $8,00 \mathrm{~h}$ & 480,00 & $8,00 \mathrm{~h}$ & 480,00 & $8,00 \mathrm{~h}$ & 480,00 & $8,00 \mathrm{~h}$ & 480,00 \\
\hline Subtotal $(\mathrm{R} \$)$ & - & $1.280,00$ & - & $1.280,00$ & - & $1.280,00$ & - & $1.280,00$ \\
\hline Subtotal $1(\mathrm{R} \$)$ & - & $5.665,09$ & - & $5.564,50$ & - & $5.492,64$ & - & $5.438,18$ \\
\hline \multicolumn{9}{|l|}{ 2. Custos Fixos } \\
\hline Benfeitoria & 243 dias & 364,5 & 243 dias & 364,5 & 243 dias & 364,5 & 243 dias & 364,5 \\
\hline $\begin{array}{l}\text { Remuneração da } \\
\text { terra }^{3}\end{array}$ & 1,00 ha & 1350,00 & 1,00 ha & 1350,00 & 1,00 ha & 1350,00 & 1,00 ha & 1350,00 \\
\hline Subtotal 2(R\$) & - & 1714,50 & - & $\mathbf{1 7 1 4 , 5 0}$ & - & $\mathbf{1 7 1 4 , 5 0}$ & - & $\mathbf{1 7 1 4 , 5 0}$ \\
\hline \multicolumn{9}{|l|}{ 3. Outros custos } \\
\hline Imprevisto(10\% ST1) & - & 566,51 & - & 556,45 & - & 549,26 & - & 543,82 \\
\hline $\begin{array}{l}\text { Administração } \\
(5 \% \text { ST1 })\end{array}$ & & 283,25 & - & 278,23 & & 274,63 & & 271,91 \\
\hline Subtotal 3 & - & 849,76 & - & 834,68 & - & 823,90 & - & 815,73 \\
\hline TOTAL & & 8229,35 & - & 8113,68 & - & 8031,04 & - & 7968,41 \\
\hline 0,0046 & 9 & 340,70 & - & 335,91 & - & 332,48 & - & 329,89 \\
\hline TOTAL GERAL/ha & & 8570,05 & - & 8449,58 & - & 8363,52 & - & 8298,30 \\
\hline
\end{tabular}

Adaptado de Gassi et al. (2014). ${ }^{1}$ Custo: Peso das mudas multiplicado pelo preço de $\mathrm{R} \$ 2,00 \mathrm{~kg}^{-1}$ pago ao produtor. Fonte: Vendedores de hortaliças no varejo em Maringá-PR, em 2014. 
Tabela 4 - Custos de produção de um hectare de mangarito cultivado com adição de cama de frango e sob diferentes espaçamentos entre plantas.

\begin{tabular}{|c|c|c|c|c|c|c|c|c|}
\hline \multirow{2}{*}{$\begin{array}{l}\text { Espaçamento } \\
(\mathrm{cm})\end{array}$} & \multicolumn{2}{|c|}{12,5} & \multicolumn{2}{|c|}{15} & \multicolumn{2}{|c|}{17,5} & \multicolumn{2}{|c|}{20} \\
\hline & Quant. & Custo $(\mathrm{R} \$)$ & Quant. & Custo $(\mathrm{R} \$)$ & Quant. & Custo $(\mathrm{R} \$)$ & Quant. & Custo $(\mathrm{R} \$)$ \\
\hline \multicolumn{9}{|l|}{ Insumos } \\
\hline Mudas $^{1}$ & 302,54 & 605,09 & 252,25 & 504,50 & 216,32 & 432,64 & 189,09 & 378,18 \\
\hline Cama de frango ${ }^{2}$ & $10 \mathrm{t}$ & 900 & $10 \mathrm{t}$ & 900 & $10 \mathrm{t}$ & 900 & $10 \mathrm{t}$ & 900 \\
\hline Subtotal $(\mathrm{R} \$)$ & - & $1.505,09$ & - & $1.404,50$ & - & $1.332,64$ & - & $1.278,18$ \\
\hline Mão-de-obra & $\mathrm{H} / \mathrm{D}$ & $(\mathrm{R} \$)$ & $\mathrm{H} / \mathrm{D}$ & $(\mathrm{R} \$)$ & $\mathrm{H} / \mathrm{D}$ & $(\mathrm{R} \$)$ & $\mathrm{H} / \mathrm{D}$ & $(\mathrm{R} \$)$ \\
\hline Preparo das mudas & 8,00 & 360,00 & 8,00 & 360,00 & 8,00 & 360,00 & 8,00 & 360,00 \\
\hline Plantio & 16,00 & 720,00 & 16,00 & 720,00 & 16,00 & 720,00 & 16,00 & 720,00 \\
\hline Distribuição da CF & 5 & 225 & 5 & 225 & 5 & 225 & 5 & 225 \\
\hline Irrigação & 10,00 & 450,00 & 10,00 & 450,00 & 10,00 & 450,00 & 10,00 & 450,00 \\
\hline Capinas & 20,00 & 900,00 & 20,00 & 900,00 & 20,00 & 900,00 & 20,00 & 900,00 \\
\hline Colheita & 30,00 & 1350,00 & 30,00 & 1350,00 & 30,00 & 1350,00 & 30,00 & 1350,00 \\
\hline Subtotal $(\mathrm{R} \$)$ & - & $4.005,00$ & - & $4.005,00$ & - & $4.005,00$ & - & $4.005,00$ \\
\hline \multicolumn{9}{|l|}{ Maquinários } \\
\hline Bomba de irrigação & $80,00 \mathrm{~h}$ & 800,00 & $80,00 \mathrm{~h}$ & 800,00 & $80,00 \mathrm{~h}$ & 800,00 & $80,00 \mathrm{~h}$ & 800,00 \\
\hline Trator preparo & $8,00 \mathrm{~h}$ & 480,00 & $8,00 \mathrm{~h}$ & 480,00 & $8,00 \mathrm{~h}$ & 480,00 & $8,00 \mathrm{~h}$ & 480,00 \\
\hline Subtotal $(\mathrm{R} \$)$ & - & $1.280,00$ & - & $1.280,00$ & - & $1.280,00$ & - & $1.280,00$ \\
\hline Subtotal $1(\mathrm{R} \$)$ & - & $6.790,09$ & - & $6.689,50$ & - & $6.617,64$ & - & $6.563,18$ \\
\hline \multicolumn{9}{|l|}{ 2. Custos Fixos } \\
\hline Benfeitoria & 243 dias & 364,5 & 243 dias & 364,5 & 243 dias & 364,5 & 243 dias & 364,5 \\
\hline $\begin{array}{l}\text { Remuneração da } \\
\text { terra }^{3}\end{array}$ & 1,00 ha & 1350,00 & 1,00 ha & 1350,00 & 1,00 ha & 1350,00 & 1,00 ha & 1350,00 \\
\hline Subtotal 2(R\$) & - & 1714,50 & - & 1714,50 & - & 1714,50 & - & 1714,50 \\
\hline \multicolumn{9}{|l|}{ 3. Outros custos } \\
\hline Imprevisto(10\% ST1) & - & 679,01 & - & 668,95 & - & 661,76 & - & 656,32 \\
\hline $\begin{array}{l}\text { Administração } \\
(5 \% \text { ST1) }\end{array}$ & - & 339,50 & - & 334,48 & - & 330,88 & - & 328,16 \\
\hline Subtotal 3 & - & 1018,51 & - & 1003,43 & - & 992,65 & - & 984,48 \\
\hline TOTAL & - & $9.523,10$ & - & $9.407,43$ & - & $9.324,79$ & - & $9.262,16$ \\
\hline 0,0046 & 9 & 394,26 & 9 & 389,47 & 9 & 386,05 & 9 & 383,45 \\
\hline TOTAL GERAL/há & - & $9.917,36$ & - & $9.796,89$ & - & $9.710,83$ & - & $9.645,61$ \\
\hline
\end{tabular}

Adaptado de Gassi et al. (2014). ${ }^{1}$ Custo: Massa das mudas multiplicada pelo preço de $\mathrm{R} \$ 2,00 \mathrm{~kg}^{-1}$ pago ao produtor. Fonte: Vendedores de hortaliças no varejo em Maringá-PR, em 2014. ${ }^{2}$ Custo da cama de frango $=\mathrm{R} \$ 90,00$ por tonelada.

Considerando-se a produtividade de massa fresca dos rizomas comerciais de mangarito (Tabela 5), os custos de produção (Tabelas 3 e 4) e a estimativa das rendas bruta e líquida (Tabela 5), observa-se que o cultivo de mangarito com espaçamento de $12,5 \mathrm{~cm}$ com a adição de cama de frango base casca de arroz ao solo, proporcionou a maior produção de rizomas filhos comerciais $(5,17 \mathrm{t}$ $\left.\mathrm{ha}^{-1}\right)$, maior renda bruta $(\mathrm{R} \$ 15.517,50)$ e maior renda líquida ( $\mathrm{R} \$ 5.600,14)$.

A menor produtividade $\left(1,40 \mathrm{t} \mathrm{ha}^{-1}\right)$, a menor renda bruta $(\mathrm{R} \$ 4.207,50)$ e a menor renda líquida $(\mathrm{R} \$-5.438,11)$ foram observadas no cultivo com espaçamento de $20 \mathrm{~cm}$ e com a adição de cama de frango base de maravalha. Esses resultados apontam que o produtor deve ter cautela na escolha das técnicas de cultivo, pois o mesmo pode obter produtividades relativamente altas, mas com custos de produção elevados, diminuindo a rentabilidade.

Os resultados obtidos neste estudo confirmam o exposto por Perez Júnior, Oliveira e Costa 2012, em relatos feitos sobre gestão estratégica de custos, quando citam que a análise econômica deve ser realizada a fim de conhecer com mais detalhes a estrutura produtiva da atividade e realizar as alterações necessárias ao aumento de sua eficiência. 
Tabela 5 - Produtividade de massa fresca, renda bruta, custo de produção e renda líquida de plantas de mangarito cultivados sob diferentes espaçamentos entre plantas e tipos de cama de frango com diferentes bases.

\begin{tabular}{|c|c|c|c|c|}
\hline Espaçamentos (cm) & $\begin{array}{l}\text { Produtividade } \\
\left(\mathrm{t} \mathrm{ha}^{-1}\right)\end{array}$ & $\begin{array}{c}\text { Renda bruta } \\
\left(\mathrm{R} \$ \text { ha }^{-1}\right)\end{array}$ & $\begin{array}{c}\text { Custos } \\
\text { de produção } \\
\left(\mathbf{R} \$ \text { ha }^{-1}\right)\end{array}$ & $\begin{array}{l}\text { Renda líquida } \\
\left(\mathrm{R} \$ \mathrm{ha}^{-1}\right)\end{array}$ \\
\hline \multicolumn{5}{|l|}{ Sem cama de frango } \\
\hline 12,5 & 3,61 & $10.845,00$ & $8.570,05$ & $2.274,95$ \\
\hline 15 & 3,20 & $9.615,00$ & $8.449,58$ & $1.165,42$ \\
\hline 17,5 & 3,22 & $9.652,50$ & $8.363,52$ & $1.288,98$ \\
\hline 20 & 3,35 & $10.065,00$ & $8.298,30$ & $1.766,70$ \\
\hline \multicolumn{5}{|l|}{ Cama base maravalha } \\
\hline 12,5 & 4,38 & $13.155,00$ & $9.917,36$ & $3.237,64$ \\
\hline 15 & 2,04 & $6.135,00$ & $9.796,89$ & $-3.661,89$ \\
\hline 17,5 & 4,14 & $12.435,00$ & $9.710,83$ & $2.724,17$ \\
\hline 20 & 1,40 & $4.207,50$ & $9.645,61$ & $-5.438,11$ \\
\hline \multicolumn{5}{|l|}{ Cama base casca de arroz } \\
\hline 12,5 & 5,17 & $15.517,50$ & $9.917,36$ & $5.600,14$ \\
\hline 15 & 4,81 & $14.430,00$ & $9.796,89$ & $4.633,11$ \\
\hline 17,5 & 2,94 & $8.812,50$ & $9.710,83$ & $-898,33$ \\
\hline 20 & 3.64 & $10.912,50$ & $9.645,61$ & $1.266,89$ \\
\hline
\end{tabular}

${ }^{1} \mathrm{R} \$ 3,00 \mathrm{~kg}^{-1}$ - valor pago ao produtor em comércio especializado de Dourados - MS em janeiro de 2017.

\section{CONCLUSÕES}

$\mathrm{O}$ cultivo de mangarito realizado com o espaçamento de $12,5 \mathrm{~cm}$ entre plantas e com adição de cama de frango base de casca de arroz resultou na maior produtividade de rizomas comercializáveis.

O menor custo de produção correspondeu ao espaçamento de $20 \mathrm{~cm}$ entre plantas sem a adição de cama de frango.

As maiores rendas bruta e líquida foram obtidas quando se cultivou o mangarito sob espaçamento de $12,5 \mathrm{~cm}$ entre plantas e com a adição de cama de frango base casca de arroz.

\section{AGRADECIMENTOS}

À CAPES e ao CNPq, pela concessão das bolsas, e à FUNDECT, pelo apoio financeiro.

\section{REFERÊNCIAS}

CHEN, B.; LIU, E.; TIAN, Q.; YAN, C.; ZHANG, Y. Soil nitrogen dynamics and crop residues. A review. Agronomy for Sustainable Development, v. 34, p. 429-442. 2014.2 Disponível em: https://link.springer.com/article/10.1007/s13593014-0207-8. Acesso em: 07 jun. 2017.
COSTA, C. A.; RAMOS, S. J.; ALVES, D. S.; FERNANDES, L. A.; SAMPAIO, R. A.; MARTINS, E. R. Nutrição mineral do mangarito num Latossolo Vermelho Amarelo. Horticultura Brasileira, v. 26, n. 1, p. 102-106, jan./mar. 2008. Disponível em: http://www.scielo.br/pdf/hb/v26n1/a20v26n1.pdf. Acesso em: 05 jan. 2017.

EMPRESA BRASILEIRA DE PESQUISA AGROPECUÁRIA. 2010. Sistema de produção do milho. Minas Gerais: Embrapa/Milho e Sorgo. 2010. Disponível em: http://www.cnpms.embrapa.br/publicacoes/milho_ 6_ed/index.htm. Acesso em: 07 Jan. 2017.

EMPRESA BRASILEIRA DE PESQUISA AGROPECUÁRIA. 2013. Sistema brasileiro de classificação de solos. 3. ed. Rio de Janeiro: Embrapa Solos, 2013, 306 p. Disponível em: https://www.embrapa.br/busca-de-produtosprocessos-e-servicos/-/produtoservico/1299/sistema-brasileiro-de-classificacao-desolos---sibcs-3-edicao. Acesso em: 10 jun. 2017. 
FERREIRA, D. F. Sisvar: a computer statistical analysis system. Ciência e Agrotecnologia, v. 35, n. 6, p. 1039-1042, nov./dez. 2011. Disponível em: http://www.scielo.br/pdf/cagro/v35n6/a01v35n6. Acesso em: 10 jun. 2017.

FONTES, P. C. R.; NUNES, J. C. S.; MOREIRA, M. A. Produção classificada de batata em resposta ao espaçamento e critério de recomendação da adubação. Bioscience Journal, v. 28, n. 3, p. 404-412. 2012. Disponível em: http://www.seer.ufu.br/index.php/biosciencejournal /article/view/12497/9585. Acesso em: 08 jun. 2017.

FRAGATA, C. 2012. Patrimônio nacional: de volta à raiz. Revista Gosto. Disponível em: http://www.revistagosto.com.br/portal/materia/ma ngarito/mangarito materiatemplate.aspx. Acesso em: 22 Dez. 2016.

GASSI, R. P. Produção agroeconômica e bromatologia do mangarito (Xanthosoma mafaffa Schott) cultivado sob diferentes tratos culturais em Dourados-MS. 2010. 43f. Tese (Doutorado em Agronomia) - Universidade Federal da Grande Dourados, Dourados, 2010.

GASSI, R. P.; HEREDIA ZÁRATE, N. A.; VIEIRA, M. C.; TORALES, E. P. Desempenho agroecônomico do mangarito 'Comum' cultivado com espaçamentos entre plantas e massas de rizomassemente. Semina: Ciências Agrárias, v. 35, n. 1, p.149160, jan./fev. 2014. Disponível em: http://www.redalyc.org/articulo.oa?id=44574413901 2. Acesso em: 05 jan. 2017.

HEID, D. M.; HEREDIA ZÁRATE, N. A.; VIEIRA, M. C.; TORALES, E. P.; CARNEVALI, T. O.; MARAFIGA, B. G. Produtividade agroeconômica de mandioquinha-salsa em resposta à adição de cama-de-frango no solo. Semina: Ciências Agrárias, v. 36, n. 3, suplemento 1, p. 1835-1850, $2015 . \quad$ Disponível em: http://www.uel.br/revistas/uel/index.php/semagrari as/article/view/14868/16447. Acesso em: 10 jun. 2017.
HEREDIA ZÁRATE, N. A.; SANGALLI, C. M. S.; VIEIRA, M. C.; JORGE, R. P. G.; TORALES, E. P.; SALLES, N. A. Produção agroeconômica do mangarito submetido a diferentes arranjos espaciais e tratos culturais. Horticultura Brasileira, v. 31, n. 3, p. 476-482, jul./set. 2013. Disponível em: http://www.scielo.br/pdf/hb/v31n3/22.pdf. Acesso em: 10 jun. 2017.

HEREDIA ZÁRATE, N. A.; VIEIRA, M. C.; HELMICH, M.; MARIA, M. A. Tamanho de rizomas-semente e fileiras de plantas no canteiro na produção do mangarito cv. Comum. Ciência $e$ Agrotecnologia, v. 30, n. 45, p. 907-913, set./out. 2006. Disponível

em: http://www.scielo.br/pdf/cagro/v30n5/v30n5a13.p df. Acesso em: 10 abr. 2017.

HEREDIA ZÁRATE, N. A.; VIEIRA, M. C.; PONTIM, B. C. Arranjo de plantas na produção do mangarito (Xanthosoma mafaffa Schott) 'Comum'. Acta Scientiarum: Agronomy, v. 27, n. 3, p. 409-413, jul./set. $2005 . \quad$ Disponível em: http://periodicos.uem.br/ojs/index.php/ActaSciAgr on/article/view/1400/816. Acesso em: 12 nov. 2016.

HOSHINO, R. T.; ALVES, G. A. C.; MELO, T. R.; BARZAN, R. R.; FREGONEZI, G. A. F.; FARIA, R. T. Adubação mineral e orgânica no desenvolvimento de orquídea Cattlianthe 'Chocolate drop'. Horticultura Brasileira, v. 34, n. 4, out./dez. 2016. Disponível

em: http://www.scielo.br/pdf/hb/v34n4/1806-9991-hb34-04-00475.pdf. Acesso: 08 mai. 2017.

KINUPP, V.F.; LORENZI, H. Plantas alimentícias não convencionais (PANC) no Brasil: guia de identificação, aspectos nutricionais e receitas ilustradas. São Paulo: Instituto Plantarum de Estudos da Flora, 2014. 768 p.

MANGIORI, V. R. L.; FILHO, J. T. Disposição de resíduos sólidos no solo: efeitos nos atributos físicos, químicos e na matéria orgânica. Semina: Ciências Agrárias, v. 36, n. 2, p. 747-764, mar./abr. 2015. Disponível

em: http://www.uel.br/revistas/uel/index.php/semagrari as/article/viewFile/16696/16112. Acesso em: 08 mai. 2017. 
MELO, A. S.; COSTA, B. C.; BRITO, M. E. B.; AGUiAR NETO, A. O.; VIÉGAS, P. R. A. Custo e rentabilidade na produção de batata-doce nos perímetros irrigados de Itabaiana-Sergipe. Pesquisa Agropecuária Tropical, v. 39, n. 2, p. 119-123, abr./jun. $2009 . \quad$ Disponível em: https://ri.ufs.br/bitstream/123456789/1258/1/Cust oERentabilidade.pdf. Acesso em: 05. Jan. 2017.

PEEL, M. C., FINLAYSON, B. L., MCMAHON, T. A. Updated world map of the Köppen-Geiger climate classification. Hydrology and Earth System Sciences, v. 11, p. 1633-1644, 2007. Disponível em: http://www.hydrol-earth-syst-

sci.net/11/1633/2007/hess-11-1633-2007.pdf.

Acesso em: 05 jan. 2017.

PEIXOTO, C. P.; GONÇALVES, J. A.; PEIXOTO, M. F. S. P.; CARMO, D. O. Características agronômicas e produtividade de amendoim em diferentes espaçamentos e épocas de semeadura no Recôncavo Baiano. Bragantia, v. 67, n. 3, p. 673-684, 2008. Disponível em: http://www.scielo.br/pdf/brag/v67n3/a16v67n3.pd f. Acesso em: 05 jan. 2017.

PEREIRA, A. P.; VILLA NOVA, N. A.; RAMOS, V. J.; PEREIRA, A. R. Potato potential yield based on climatic elements and cultivar characteristics. Bragantia, v. 67, p. 327-334, 2008. Disponível em: http://dx.doi.org/10.1590/S0006-

87052008000200008 . Acesso em: 08 jun. 2017.

PEREZ JUNIOR, J. H.; OLIVEIRA, L. M.; COSTA, R. G. Gestão estratégica de custos. Atlas, São Paulo, Brasil. 2012, 360 p.
ROCHA, D. R. Desempenho de cultivares de milho verde submetidas a diferentes populações de plantas em condições de irrigação. 2008. 89f. Tese (Doutorado em Agronomia) - Universidade Estadual Paulista, Jaboticabal, 2008. Disponível em: http://hdl.handle.net/11449/105296. Acesso em: 10 jun. 2017.

ROCHA, D. R; FILHO, D. F.; BARBOSA, J. C. 2013. Efeitos da densidade de plantas no rendimento comercial de espigas verdes de cultivares de milho. Horticultura Brasileira, v. 29, n. 3, p. 392-397, jul./set. 2011. Disponível em: http://www.scielo.br/pdf/hb/v29n3/v29n3a23.pdf. Acesso em: 08 mai. 2017.

TAIZ, L.; ZEIGER, E. Fisiologia Vegetal. 5. ed. Porto Alegre: Artmed, 2013, 945 p.

TERRA, T. G. R.; LEAL, T. C. A. B.; SIEBENEICHLER, S. C.; CASTRO, D. V.; DIAS NETO, J.; ANJOS, L. M. Desenvolvimento e produtividade de sorgo em função de diferentes densidades de plantas. Bioscience Journal, v. 26, n. 2, p. 208-215, mar./abr. 2010. Disponível em: http://www.seer.ufu.br/index.php/biosciencejournal /article/view/7065/4681. Acesso em: 05 jan. 2017.

TORALES, E. P.; HEREDIA ZÁRATE, N. A.; VIEIRA, M. C.; GASSI, R. P.; SALLES, N. A.; PINTO, J. V. C. Influência da cama de frango e de espaçamentos entre plantas na produtividade agroeconômica de mandioquinha-salsa. Revista Ceres, v. 61, n. 2, p. 162-171, mar./abr. 2014. Disponível em:

http://www.scielo.br/pdf/rceres/v61n2/v61n2a02.p df. Acesso em: 20 dez. 2016. 